Research Paper

\title{
Farmers preferences of communication sources in perception of farm technology
}

S.K. NAYAK AND D.P. RAI

\begin{abstract}
Information channels in modern era are crucial in transfer of farm technology among the farmers further leading to initiate the process of converting in actual practical application to enhance the production.
\end{abstract}

KEY WORDS : Communication sources, Utilization, Usefulness

How to cite this Article : Nayak, S.K. and Rai, D.P. (2014). Farmers preferences of communication sources in perception of farm technology. Engg. \& Tech. in India, $\mathbf{5}(1 \& 2): 22-25$. 